\title{
Direct-Mode Glucose Fuel Cells with Near-Neutral-State Electrolytes: Anode Electrode Studies with Different Catalysts and Electrolytes
}

\author{
J.-P. Spets ${ }^{*}, 1$, Y. Kiros ${ }^{2}$, T. Noponen ${ }^{1}$, M.A. Kuosa ${ }^{1}$, J. Rantanen ${ }^{3}$, M.J. Lampinen ${ }^{1}$ and K. Saari ${ }^{1}$ \\ ${ }^{I}$ Helsinki University of Technology, Department of Energy Technology, Applied Thermodynamics, P.O. Box 4400, FI- \\ 02150 TKK, Finland \\ ${ }^{2}$ Royal Institute of Technology-KTH, Department of Chemical Engineering and Technology, S100-44 Stockholm, \\ Sweden \\ ${ }^{3}$ Oy Hydrocell Ltd, Minkkikatu 1-3, FI-04430 Järvenpää, Finland
}

\begin{abstract}
In the present study, a direct-mode glucose fuel cell with a neutral-state and near-neutral-state aqueous electrolytes is studied. The near-neutral state electrolytes are important for two reasons. Firstly, the $\mathrm{pH}$ of the electrolytes would be near the $\mathrm{pH}$ of liquid in living cells. Secondly, the neutral electrolyte would enable good corrosion resistance of catalyst materials. Three different catalyst materials, i.e. Pt-Pd, Raney-Ni and Ni-porphyrin complex, are tested in an anode half-cell configuration with one neutral-state (battery water) and with two near-neutral-state aqueous electrolytes, i.e. modified Krebs-Ringer (K-R) and phosphate, both buffered to a pH value of 7.4. Pt-Pd catalyst in the aqueous K-R electrolyte maintains the negative voltage of the anode half cell with higher current densities that the nickel catalysts do. To estimate the operation of the direct-mode glucose fuel cell, the K-R electrolyte from the anode half-cell tests is tested also in the cathode half-cell with combined catalyst of cobalt porphyrin complex and of spinel. The open circuit voltages and polarisation curves are measured. Also, preliminary results and oxidation degrees of glucose in the tests are shown. Based on our half cell measurements, there are high development demands for the electro-catalysts, which could work efficiently in the near-neutral-state electrolytes.
\end{abstract}

Keywords: Anode and cathode half-cells, neutral-state and near-neutral-state electrolytes, direct-mode glucose fuel cell.

\section{INTRODUCTION}

A direct-mode glucose fuel cell is of great importance, because glucose can be produced easily by hydrolysis from starch and cellulose, both of which are complex storage carbohydrates in nature [1]. In this study, a direct-mode glucose anode half-cell with three different catalyst materials is tested. Also a direct-mode glucose cathode half-cell is tested with one catalyst material. The target is to produce both effective and simple direct-mode glucose fuel cell either with a neutral or near-neutral-state electrolyte, which could operate with a moderate electric power production capacity of few $\mathrm{mWcm}^{-2}$. The neutral-state and near-neutral-state electrolyte were selected for two reasons. Firstly, the $\mathrm{pH}$ of the electrolyte would be near the $\mathrm{pH}$ of liquid in living cells. Secondly, the neutral electrolyte would enable good corrosion resistance of catalyst materials. There exist other kinds of applications that utilise enzymes or bacterial culture for reforming of bio fuels in fuel cell applications [2, 3]. Concerning the direct-mode glucose applications, if the fuels for fuel cell operation were dissolved in an electrolyte, there would be no need for auxiliary reforming equipment or additional bacterial cultures. Also, a direct-mode operation for glucose-driven fuel cells would not need any proton

*Address correspondence to this author at the Helsinki University of Technology, Department of Energy Technology, Applied Thermodynamics, Sähkömiehentie 4 J, P.O. Box 4400, FI-02150 TKK, Finland; Tel: +358(0)9-451 3992, -4511; Fax: +358-(0)9-4553724;

E-mail: jukka-pekka.spets@tkk.fi selective or anion conductive membranes. In the development of direct-mode glucose fuel cells there is the target to enable a high electronic yield and electric power production from one molecule of glucose. In earlier studies with glucose or other carbohydrates as a fuel in the direct or the direct fuel cells or in the direct-mode fuel cells or halfcells, the metallic catalyst materials have been used in neutral, in alkaline or in acidic electrolytes [5-10]. The oxidation reactions of glucose have occurred to a limited degree. The yield of electrons from one glucose molecule in the direct-mode fuel cells has been only two electrons from 24 available electrons, as in Refs. [4, 11]. In many reports, the anode catalyst materials have been composed of different Pt alloys [4, 8-14]. In this study, three different catalyst materials (Pt-Pd, Raney-Ni, and Ni-Porphyrin complex) in an anode direct-mode half-cell with a neutral state electrolyte are tested. To estimate the operation capacity of the directmode fuel cell, the electrolyte, which produces the best results in the anode half cell, is tested also in a cathode half cell. A combined catalytic material of cobalt porphyrin complex CoTPP and of spinell $\mathrm{MnCo}_{2} \mathrm{O}_{4}$ is used as the cathode catalyst in the test.

\section{EXPERIMENTAL}

In our tests both the direct-mode half-cells consist of an electrode with changing catalyst material, counter electrode, and reference electrode (SHE). The cathode half cell equipment also includes an air fan (a pc cooling fan) for feeding oxygen. The catalyst geometrical areas in all tests are in order of magnitude of $10 \mathrm{~cm}^{2}$. The catalyst loadings in 
the anode electrode are in the order of magnitude of 3.75 $\mathrm{mgcm}^{-2}(10 \%$ on carbon) for both Pt and Pd in the Pt-Pd catalyst (commercial product by Johnson Matthey), of $300 \mathrm{mgcm}^{-2}$ for the Raney-Nickel catalyst (by Gaskatel), and of $300 \mathrm{mgcm}^{-2}$ for the catalyst of Nickel-Porphyrin complex (by Acta), respectively. The catalyst loadings in a cathode half-cell contain a combined catalyst loading of $3.15 \mathrm{mg} \mathrm{cm}^{-}$

2 of CoTPP (by Hydrocell) with a concentration of $18 \%$ on carbon and of $17.5 \mathrm{mg} \mathrm{cm}^{-2}$ of $\mathrm{MnCo}_{2} \mathrm{O}_{4}$ (by Hydrocell). All the catalyst structures have $1.5 \mathrm{~g}$ diffusion layers (acetylene carbon black and Teflon). The distances between counter electrodes are $8 \mathrm{~mm}$ in the both half-cells in this study.

Battery water (i.e. deionised water) is used as the neutralstate electrolyte is used. According to Refs $[8,15]$, the aqueous near-neutral-state electrolytes in the tests are modified Krebs-Ringer (K-R) and $\mathrm{KH}_{2} \mathrm{PO}_{4}$ buffer solutions. These electrolytes are buffered to a $\mathrm{pH}$ value of 7.4. The Krebs-Ringer solution is buffered with $\mathrm{NaHCO}_{3}$ powder and the $\mathrm{KH}_{2} \mathrm{PO}_{4}$ solution is buffered with $\mathrm{NaOH}$ powder. The $\mathrm{pH}$ values of the different electrolytes are measured with a Eutech $\mathrm{pH}$ test 30 measurement. The conductivity values of each electrolyte are measured with Cyberscan Con 510 conductivity measurement. In Table $\mathbf{1}$, the composition values of the electrolytes are shown.

Table 1. The Chemical Compositions of the Near-Neutral State Electrolytes in the Anode Half Cell Tests

\begin{tabular}{|c|c|}
\hline Modified Krebs-Ringer $^{8}$ & Concentration [M] \\
\hline \hline $\mathrm{NaCl}$ & 0.122 \\
\hline $\mathrm{KCl}$ & 0.005 \\
\hline $\mathrm{KH}_{2} \mathrm{PO}_{4}$ & 0.001 \\
\hline $\mathrm{MgSO}_{4} * 7 \mathrm{H}_{2} \mathrm{O}$ & 0.001 \\
\hline $\mathrm{NaHCO}_{3}$ & 0.025 (order of magnitude) \\
\hline $\mathbf{K H 2 P O 4}+\mathrm{NaOH}^{15}$ & Concentration [M] \\
\hline \hline $\mathrm{KH}_{2} \mathrm{PO}$ & 0.1 \\
\hline $\mathrm{NaOH}$ & 0.1 (order of magnitude) \\
\hline All chemicals were from Sigma Aldrich. & \\
\hline
\end{tabular}

The test routine in all the tests with the near-neutral-state electrolytes in the anode half cell is as follows: 1 . Preparation of the aqueous electrolytes with glucose, but without the alkali insert. 2 . Buffering the $\mathrm{pH}$ value of the solution in 7.4 with alkali insert. 3. Measurement of the conductivity of the buffered solution. 4. Adding the solution in the anode half-cell. 5. The anode catalyst material was activated by flushing hydrogen gas into the anode half-cell during a time period of 10 to 15 seconds. To avoid a remainder of hydrogen gas residues on the catalyst's surface after the activation, in the half-cell operation, charging and discharging cycles were performed three times in each test. 6. Measurement of the generation of an open circuit voltage (OCV). 7. After the generation of the OCV, the polarisation curves are recorded in each case. An auxiliary device (Velleman, PS 613, DC) is used as a resistor. When the resistor has a value of $1.4 \mathrm{~V}$, the test is stopped to prevent the electrical decomposition of water. 8. The $\mathrm{pH}$ value of the electrolyte in the half-cell is measured.

The test routine in the test with the cathode half cell is as follows: 1. Preparation of the aqueous electrolyte with glucose, but without the alkali insert. 2. Buffering the $\mathrm{pH}$ value of the solution to a $\mathrm{pH}$ value of 7.4 with alkali insert. 3 . Measurement of the conductivity of the buffered solution. 4. Adding the solution in the anode half-cell. 5. The starting of the air fan for feeding oxygen in the anode half-cell. 6 . Measurement while generating an open circuit voltage (OCV). 7. After the generation of the OCV, the polarisation curves are recorded in each case. An auxiliary device (Velleman, PS 613, DC) is used as a resistor. When the resistor has a value of $1.4 \mathrm{~V}$, the test is stopped to prevent the electrical decomposition of water. 8. The $\mathrm{pH}$ value of the electrolyte in the half-cell is measured.

Before the measurements, we tested the appropriateness of our test routine with the near-neutral-electrolyte by comparing the measured OCV values of glucose, of ethanol and of fructose in an anode half-cell to the values measured and reported earlier in Ref. [8]. The anode catalyst was Pt-Pd and the electrolyte was aqueous modified Krebs-Ringer solution buffered to a $\mathrm{pH}$ value of 7.4. This comparison is shown in Table 2.

Table 2. Comparison of Our Test Methods to the Test Method Used Earlier in Ref. [8]. The Anode HalfCell has a Modified Krebs-Ringer Electrolyte, and has Pt-Pd or Pt as a Catalyst. All Fuels have Concentrations of $5 \mathrm{mM}$

\begin{tabular}{|c|c|c|c|}
\hline Fuel & pH at Start & OCV Measured & OCV in Ref. [8] \\
\hline \hline Glucose & 7.4 & -0.22 & -0.22 \\
\hline Ethanol & 7.4 & -0.18 & -0.18 \\
\hline Fructose & 7.4 & -0.22 & -0.22 \\
\hline
\end{tabular}

In Table 2, the OCV values for glucose, ethanol and fructose, all of $5 \mathrm{mM}$ concentrations show the values to be exactly the same as the OCV values reported earlier in Ref. [8]. It is therefore suggested that our test method in the tests is accessible, and most of the current results from the oxidation of fuel. The consecutive threefold discharging and charging cycles help to avoid any residue of hydrogen gas remaining on the surface of the catalysts.

\section{THE LIMITATIONS OF THE SCOPE OF THE RESULTS}

The power output was found to be negligible when the neutral-state electrolyte (battery water) was used in the test anode half cell. The measured current densities were low. Therefore, the test results in this study mainly concern only the near-neutral-state electrolytes. The reason for the negligible results with battery water is explained with the following: The glucose molecule is dissolving in water as a molecule. The previous was demonstrated in a test, in which glucose was dissolved in a tap water. The conductivity of the tap water was measured to be $187 \mu \mathrm{S} / \mathrm{cm}\left(\right.$ at $21.8^{\circ} \mathrm{C}$ ). When glucose was dissolved in the tap water in concentration of $1 \mathrm{M}$, the conductivity of the aqueous solution was decreased 
down to value $9.61 \mu \mathrm{S} / \mathrm{cm}$ (at $22.1{ }^{\circ} \mathrm{C}$ ). Therefore the conductivity value of the aqueous solution is decreased because glucose molecule is not ionised while the dissolving. The low current value showed that the catalyst of the anode half cell was not active on glucose molecule in the neutralstate electrolyte.

\section{RESULTS AND DISCUSSION}

The $\mathrm{pH}$ and conductivity values of the electrolyte solutions with added glucose before each test at room temperature (RT) are shown in Table 3.

Table 3. Properties of the Aqueous Electrolytes Before the Operation in the Anode Half Cell. The Values are Measured at Room Temperatures (RT)

\begin{tabular}{|c|c|c|c|}
\hline $\begin{array}{c}\text { Fuel } \\
\text { [Concentration] }\end{array}$ & $\begin{array}{c}\text { Aqueous } \\
\text { Electrolyte }\end{array}$ & $\mathbf{p H}$ & $\begin{array}{c}\text { Conductivity } \\
{\left[\mathbf{m S c m}^{-1}\right]}\end{array}$ \\
\hline \hline Glucose $[5 \mathrm{mM}]$ & Modified Krebs-Ringer & 7.4 & 14.67 \\
\hline Glucose $[1 \mathrm{M}]$ & - “- & 7.4 & 9.75 \\
\hline Glucose $[5 \mathrm{mM}]$ & $\mathrm{KH}_{2} \mathrm{PO}_{4}+\mathrm{NaOH}$ & 7.4 & 13.05 \\
\hline Glucose $[1 \mathrm{M}]$ & - “ - & 7.4 & 8.34 \\
\hline
\end{tabular}

The results from the each of the tests are shown in the following. The discussion of the results is shown at the end of this chapter. Fig. (1) shows the polarization curves with glucose as the fuel in the anode half-cell, which was equipped with a Pt-Pd catalyst. Glucose was in concentrations of $5 \mathrm{mM}$ and of $1 \mathrm{M}$, respectively.

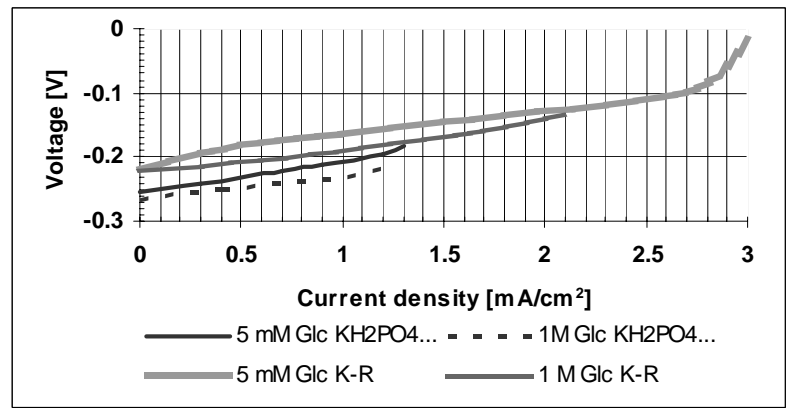

Fig. (1). Polarisation curves for glucose in an anode half-cell in two concentrations and in two electrolytes at a $\mathrm{pH}$ value of 7.4. The anode catalyst material is Pt-Pd.

Fig. (2) shows the polarisation curves with glucose as the fuel in the anode direct-mode half-cell, which was equipped with a Raney-Ni catalyst. Glucose was in concentrations of 5 $\mathrm{mM}$ and of $1 \mathrm{M}$, respectively.

Fig. (3) shows the polarisation curves with glucose as the fuel in the anode half cell, which was equipped with a catalyst of the Nickel-Porphyrin complex. Glucose was in two different concentrations of $5 \mathrm{mM}$ and of $1 \mathrm{M}$, respectively.

The OCV corresponding OCV values in Figs. (1-3) are shown in Table 4. The $\mathrm{pH}$ values of each electrolyte were 7.4 before the operation of the anode half cell. After the measurement of polarisation curves, the $\mathrm{pH}$ values were in the order of magnitude of $\mathrm{pH} 7.5$.

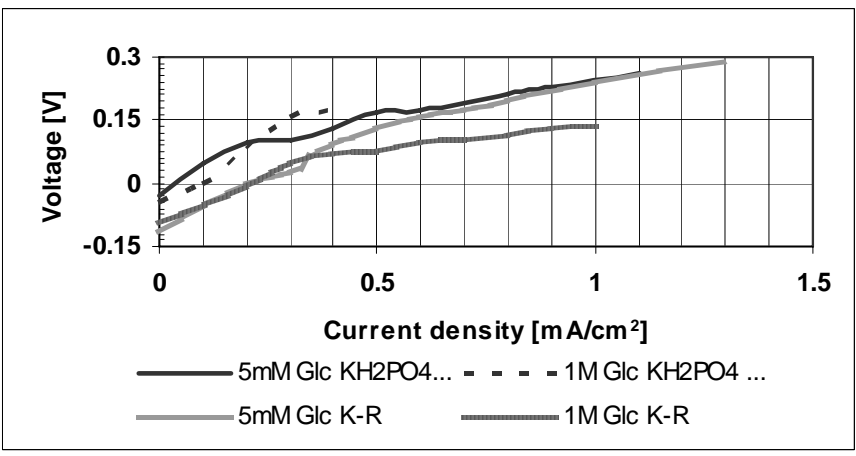

Fig. (2). Polarisation curves for glucose in an anode half-cell in two concentrations and in two electrolytes at $\mathrm{pH}$ value of 7.4. The anode catalyst material is Raney-Nickel.

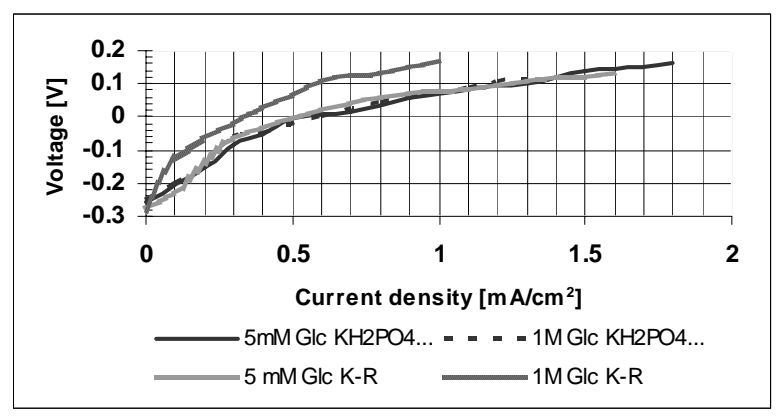

Fig. (3). Polarisation curves for glucose in an anode half-cell in two concentrations and in two electrolytes at $\mathrm{pH}$ value of 7.4. The anode catalyst material is Nickel-Porphyrin complex.

Table 4. The measured Open Current Voltage OCV Values in Each Anode Half Cell Test as Function of the Catalyst Material and Glucose Concentration in the Electrolyte

\begin{tabular}{|l|c|c|}
\hline \multicolumn{1}{|c|}{$\begin{array}{c}\text { Catalyst/ } \\
\text { Electrolyte }\end{array}$} & $\begin{array}{c}\text { OCV [V]/5 mM } \\
\text { Glucose }\end{array}$ & $\begin{array}{c}\text { OCV }[\mathbf{V}] / \mathbf{1} \text { M } \\
\text { Glucose }\end{array}$ \\
\hline \hline $\mathrm{Pt}-\mathrm{Pd} / \mathrm{K}-\mathrm{R}$ & $-0.220 \mathrm{~V}$ & $-0.223 \mathrm{~V}$ \\
\hline $\mathrm{Pt}-\mathrm{Pd} / \mathrm{KH}_{2} \mathrm{PO}_{4}$ & $-0.253 \mathrm{~V}$ & $-0.266 \mathrm{~V}$ \\
\hline Raney-Ni/K-R & $-0.117 \mathrm{~V}$ & $-0.093 \mathrm{~V}$ \\
\hline Raney-Ni/KH$/ \mathrm{PO}_{4}$ & $-0.028 \mathrm{~V}$ & $-0.045 \mathrm{~V}$ \\
\hline $\mathrm{Ni}$ - Porphyrin complex $/ \mathrm{K}-\mathrm{R}$ & $-0.278 \mathrm{~V}$ & $-0.290 \mathrm{~V}$ \\
\hline N- Porphyrin complex $/ \mathrm{KH}_{2} \mathrm{PO}_{4}$ & $-0.258 \mathrm{~V}$ & $-0.250 \mathrm{~V}$ \\
\hline
\end{tabular}

From the results shown in Figs. (1-3) and in Table 4, it can be seen that the Pt-Pd catalyst is the most effective catalyst material of the three studied ones for the direct glucose anode half-cell in the near-neutral-state electrolyte because the Pt-Pd catalyst maintains the negative voltage value of the anode half cell with higher current densities than both the nickel catalysts do. The Nickel-Porphyrin complex produces the lowest OCV values, but the voltage of the anode half cell increases fast to positive values as the current density increases. Also, differences in the anode direct-mode half-cell operation between the two electrolytes are shown. The Pt-Pd catalyst is more effective in aqueous Krebs-Ringer electrolyte than in aqueous $\mathrm{KH}_{2} \mathrm{PO}_{4}$ electrolyte at $\mathrm{pH} 7.4$ in 
the test direct glucose anode half cell. The previous is possible due to the higher conductivity values of the aqueous $\mathrm{K}-\mathrm{R}$ electrolyte as shown in Table 3. The $\mathrm{pH}$ value of 7.4 in electrolyte solution is too low a value for both nickel catalysts, which is earlier reported to be effective with electro catalytic oxidation of carbohydrates, such as primary alcohols in alkaline solutions [16]. The nickel catalyst requires an $[\mathrm{OH}]$ - ion concentration in the electrolyte high enough to work effectively in the electro-oxidation of carbohydrates. Also, the Raney-Nickel catalyst might have been oxidised very soon, because no shelter gas was used, which caused inefficient operation.

In Fig. (4) are shown the measured test results with both anode and cathode direct-mode glucose half-cells at room temperature, when the anode catalyst material was Pt-Pd and the cathode catalyst was a combined catalyst of CoTPP and of $\mathrm{MnCo}_{2} \mathrm{O}_{4}$. Aqueous $\mathrm{K}-\mathrm{R}$ was used as the electrolyte.

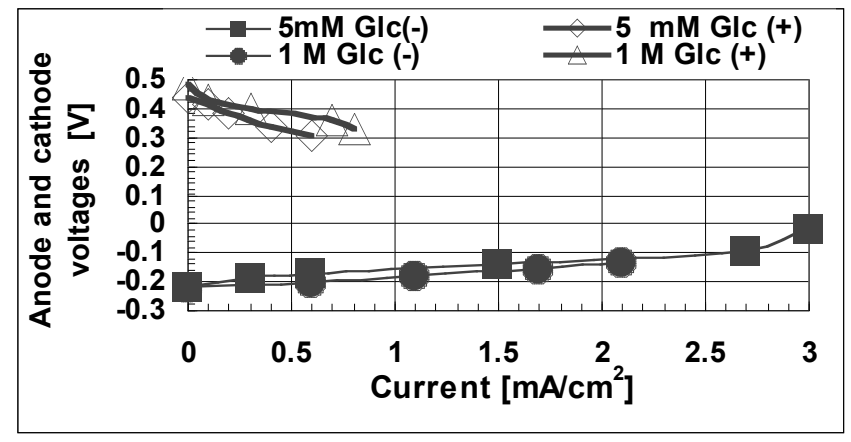

Fig. (4). The polarisation curves with glucose in two concentrations in the Krebs-Ringer electrolyte for the anode and cathode directmode half-cells at RT. Notation of (-) means the anode half-cell and notation of $(+)$ means the cathode half-cell.

From Fig. (4) can be seen that the direct-mode glucose fuel cell, with anode catalyst of Pt-Pd and combined cathode catalysts of $\mathrm{CoTPP}+\mathrm{MnCo}_{2} \mathrm{CO}_{4}$, can produce at maximum the current density of $0.8 \mathrm{~mA} / \mathrm{cm}^{2}$ with the voltage of $0.5 \mathrm{~V}$, when glucose concentration of $1 \mathrm{M}$ is dissolved in the aqueous Krebs-Ringer electrolyte.

From the earlier reports, it could be concluded that there exist several effective and selective metallic catalyst materials for electrochemical oxidation of glucose in neutral or neutral-state electrolytes other than those which were tested in this study. A more selective catalyst for glucose electro catalytic oxidation to gluconic acid $\mathrm{C}_{6} \mathrm{H}_{12} \mathrm{O}_{7}$ in alkaline solution is said to be bimetallic Pd-Bi catalyst [17]. Other promising electro oxidising catalyst materials for monosaccharides are reported to be the gold-based and the vanadium-based catalyst materials [18-19], which operate in neutral or acidic solutions. Therefore it could be interesting to test all these catalysts in the near-neutral-state electrolytes in the direct glucose anode half-cell. Increasing the selectivity of the catalyst on glucose could increase the production of the electric current from the electrochemical oxidation of glucose in the fuel cells.

The low yield of the electrons from the 24 available electrons per one molecule of glucose is suggested to be valid also for this study as it is reported earlier in Refs. $[4,11]$. This speculation is shown, even though we do not have any cyclic voltammetry analyses in the tests. In the fuel cells with the near-neutral electrolytes, the glucose molecule is oxidised mainly to gluconic acid $\mathrm{C}_{6} \mathrm{H}_{12} \mathrm{O}_{7}$. However, it can be speculated from the results in this study that changing the initial content of the glucose will cause another side-reaction or side-reactions to take place in electro catalytic oxidation of glucose. This might be possible because of the differences in the measured OCV values, which are shown in Table $\mathbf{4}$, as glucose concentration is changed in the electrolyte. Earlier it is reported, that D-sorbitol's electrocatalytic oxidation in acidic solution with Pt-catalyst material produces, at first, Dglucose. D-glucose is then oxidised in the main and side reactions to compounds, which contain Beta-glucose, glucuronic acid, different gluconolactones, and gluconic acid $[14,20]$. The fuel cell operation with near-neutral electrolyte set requirements for the catalyst materials to avoiding poisoning of these materials by the reaction products from the electrochemical oxidation reactions of the fuel. Especially Pt-Pd and Au catalyst are reported to be poisoned by gluconic acid in near neutral electrolytes [21, 22]. The PtPd catalyst being poisoned during electro-oxidation of glucose can be avoided by alloying with other materials such as $\mathrm{Sn}$ and $\mathrm{Pb}$ [13]. The neutral-state and neutral-state electrolytes in the direct-mode fuel cells, in which the fuel is dissolved in the aqueous electrolyte, could be simpler to operate and produce than the alkaline and acidic direct or direct-mode fuel cells. However, both the near-neutral-state and neutral-state electrolytes set high operational requirements for the electro-catalyst to work properly in the electro-chemical reactions because of their low conductivity values.

\section{CONCLUSIONS}

In this study, the catalyst materials of Pt-Pd, Raney-Ni and Ni-Porphyrin complex were tested in the near-neutralstate electrolyte in an anode half-cell. Of these studied catalysts, the Pt-Pd catalyst material was found to be the most effective catalyst in glucose electro catalytic oxidation because it maintained the negative voltage of the anode half cell up to the highest current densities. In the liquid phase, i.e. in the electrochemical oxidation of glucose, the gluconic acid is the main reaction product. The current density from this glucose electrochemical oxidation was detected to be in an order of magnitude from 2 to $3 \mathrm{mAcm}^{-2}$ with the negative voltage of the anode half-cell. The neutral-state and the nearneutral-state $\mathrm{pH}$ areas of electrolyte solution will not provide the best efficiencies and selectivities for the tested Pt-Pd and Ni-based catalyst materials on glucose. However, based on earlier reports, there still exist several other or alloyed catalyst materials that could be tested in the neutral-state and the near-neutral-state anode half cells. One target for the research in the future could be the development of new electro-catalysts, which enables the producing of the effective applications of the direct-mode fuel cells with the near-neutral-state electrolyte for bio-organics.

\section{ACKNOWLEDGEMENTS}

This work is supported by the Finnish Funding Agency for Technology and Innovation (TEKES) and by Finnish partners (UPM, St-1 Biofuels, Diarc, Hydrocell and the Finnish Research Centre (VTT)). Also research team in COST Action 543 is acknowledged. 


\section{REFERENCES}

[1] Dhepe, P. L.; Fukuoka, A. Cracking of cellulose over supported metal catalysts. Catal. Surv Asia, 2007, 11, 186-191.

[2] Liu Y.; Dong S. A biofuel cell with enhanced power output by grape juice. Electrochem. Commun., 2007, 9, 423-1427.

[3] Rabaey, K.; Verstraete, W. Microbial fuel cells: novel biotechnology for energy generation. Trends Biotechnol., 2005, 25, 291-298.

[4] von Stetten, F.; Kerzenmacher, S.; Lorenz, A.; Chokkalingam, V.; Miyakawa, N.; Zengerle, R.; Ducree, J. In MEMS 2006, Istanbul, Turkey, Jan 22-26, 2006, pp. 934-937.

[5] Verma, A.; Basu, S. Short communication: Direct alkaline fuel cell for multiple liquid fuels: Anode electrode studies. J. Power Sources, 2007, 174, 180-185.

[6] Verma A.; Basu, S. Direct use of alcohols and sodium borohydride as fuel in an alkaline fuel cell. J. Power Sources, 2005, 145, 282285

[7] Li, J.; Moore, C.; Kohl, P.A. Short communication: Investigation of acidic methanol solution as a fuel for microchannel fuel cells. $J$. Power Sources, 2004, 138, 211-215.

[8] Yao, S.J.; Appleby, A.J.; Geisel, A.; Cash, H.R.; Wolfson, S.K. Jr. Anodic oxidation of carbohydrates and their derivatives in neutral saline solution. Nature, 1969, 224, 921-922.

[9] Spets, J.-P.; Kiros, Y.; Rantanen, J.; Sallinen, J.; Lampinen, M.J.; Noponen, T.; Saari, K. In: Nanotech Northern Europe, Copenhagen, Denmark, September $23 \mathrm{rd}^{\mathrm{h}}$ to $25^{\text {th }}, \mathbf{2 0 0 8}$, ID: NTNE 2008-300.

[10] Spets, J.-P.; Kiros, Y.; Kuosa, M. A.; Sallinen, J.; Lampinen, M.J.; Saari, K. Starch and cellulose as fuel sources for low temperature direct mode fuel cells. Open Fuel Cells J., 2008, 1, 1-3.

[11] McKinley, J.; McHale, F.N.; Hughes, P.; Reid, C.N.; McHale, A.P. Production of electrical energy from carbohydrates using a transition metal-catalysed liquid alkaline fuel cell. Biotech. Lett., 2004, 26, 1771-1776.
[12] Enea, O. Molecular structure effects in electrocatalysis - II. oxidation of D-glucose and of linear polyols on Ni electrodes. Electrochim. Acta, 1990, 35, 375-378.

[13] Kelly, M.J.; Ingersoll, D.; Steen, W.A; Cocker, E. N.; Abraham, I. C.; Miller, J.E. Electrochemical oxidation of D-glucose at noble metal and binary metal catalyst for fuel cell applications. Abs. 736, $205^{\text {th }}$ Meeting. The Electrochemical Society Inc. (C) 2004, http://www.electrochem.org/dl/ma/205/pdfs/0736.pdf. Access: $31^{\text {st }}$ July 2009

[14] Proenca, L.; Lopes, M.I.S.; Fonseca, I.; Kokoh, K.B.; Leger, J.-M.; Lamy C. Electrocatalytic oxidation of d-sorbitol on platinum in acid medium: analysis of the reaction products. J. Electroanal. Chem., 1997, 432, 237-242.

[15] Lide, D.R.; Ed. CRC Hanbook on chemistry and physics. London, 2003.

[16] Golabi, S.M.; Nozad, A. Electrocatalytic oxidation of methanol on a nickel-porphyrin IX complex modified glassy carbon electrode in alkaline medium. Electroanalysis, 2004, 3, 199-209.

[17] Karski, S.; Paryjczak, T.; Witonska, I. Selective oxidation of glucose to gluconic acid over bimetallic Pd-Me catalysts $(\mathrm{Me}=\mathrm{Bi}$, Ti, Sn, Co). Kinet. Catal., 2003, 44, 678-682.

[18] Tominaga, M.; Nagashima, M.; Taniguchi, I. Controlled-potential electrosynthesis of glucosaminic acid from glucosamini at a gold electrode. Electrochem. Commun., 2007, 9, 911-914.

[19] Larsson, R.; Folkesson, B. A catalytic oxidation of sugar by vanadium(IV). J. Mol. Catal. A Chem., 2005, 229, 183-190.

[20] Bamba, K.; Kokoh, K.B.; Servat, K.; Leger, J. Electrocatalytic oxidation of monosaccharides on platinum electrodes modified by thallium adatoms in carbonate buffered medium. J. Appl. Electrochem., 2006, 36, 233-238.

[21] Biella S.; Prati L.; Rossi M. Selective oxidation of D-glucose on gold catalyst. J. Catal., 2002, 206, 242-247.

[22] Tominaga, M.; Nagashima, M.; Nishiyama, K.; Taniguchi, I. Surface poisoning during electrocatalytic monosaccharide oxidation reactions at gold electrodes in alkaline medium. Electrochem. Commun., 2007, 9, 1892-1898.

This is an open access article licensed under the terms of the Creative Commons Attribution Non-Commercial License (http://creativecommons.org/licenses/by$\mathrm{nc} / 3.0 /$ ) which permits unrestricted, non-commercial use, distribution and reproduction in any medium, provided the work is properly cited. 